\title{
One-pot synthesis of benzo[c]chromene-6-ones via domino Suzuki-Miyaura cross-coupling followed by oxidative lactonization catalyzed by in situ generated palladium nanoparticles under aqueous-aerobic condition
}

\author{
Jayanta K Ray* and Yasin Nuree \\ Department of Chemistry, Indian Institute of Technology, Kharagpur-721302, India \\ jkray@chem.iitkgp.ac.in yasin.nuree@gmail.com
}

Benzo[c]chromene-6-ones are the very significant class of lactones which constitute core structural subunits of various biologically and pharmaceutically active molecules ${ }^{1}$ and some important natural products $^{2}$. Natural anti-tumour agents ${ }^{3}$ such as autumnariol (Fig. 1, 1), alternariol, altenuisol, autumnariniol, and graphislactones (Fig. 1, 2), and antibiotic agents such as the galivocarcins (Fig. 1, 3), ravidomycins and chrysomycins contain these types of oxygen containing heterocycles as their core structural unit. ${ }^{3,4}$ These lactones are major structural part of naturally occurring viz. Urolithin-A (Fig. 1, 4), Urolithin-B (Fig. 1, 4), Urolithin-C which show anti-proliferative activity resisting cancer cells in animals as well as in humans. The antioxidant and important bioactive constituents of Shilajit are also these benzo[c]chrome-6-ones ${ }^{4}$. Distribution of $6 \mathrm{H}$-benzo[c]chromene-6-ones are observed widely in lichens, citrus foods, herbs, plants and some invertebrates ${ }^{5-12}$.

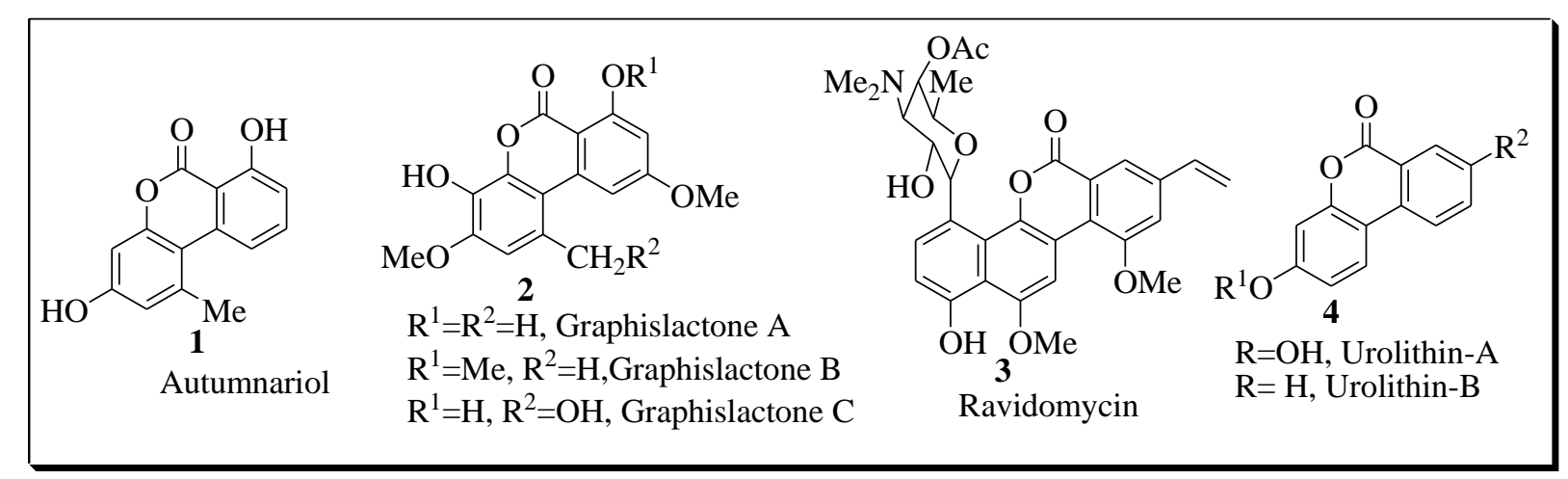

Figure 1. Structure of some natural products and bioactive compounds containing chromenone moeities

Importance of $6 \mathrm{H}$-benzo[c]chromene-6-ones for its potential therapeutic and pharmaceutical properties, has attracted researchers over the decades towards the development of more convenient and straight forward route for the synthesis of these molecules ${ }^{6-9,11-39}$.

In the past decade Bowman et al. reported $\mathrm{Bu}_{3} \mathrm{SnH}$ mediated oxidative cyclisation of 0 (benzyoxy)aryl and $o-\left[\left(\right.\right.$ aryloxy)methyl]aryl radicals. ${ }^{10,19}$ 


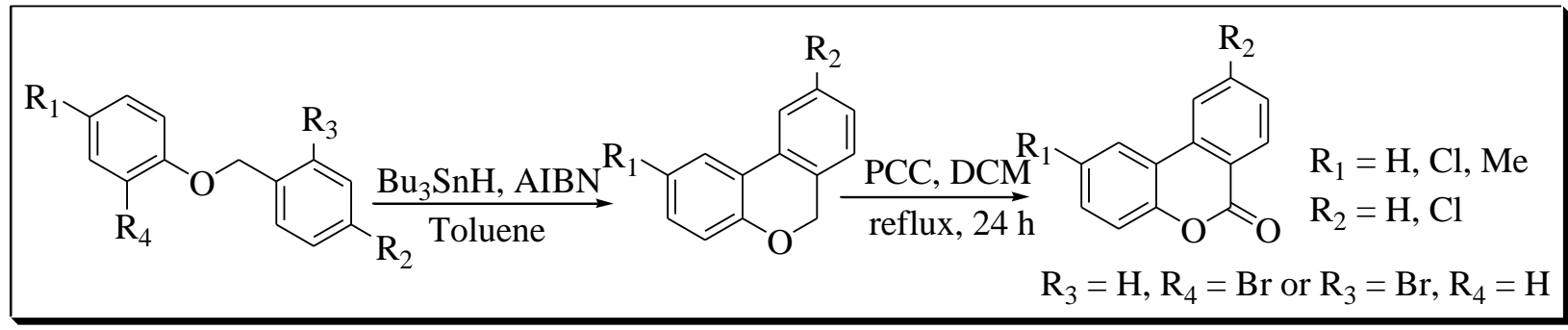

Scheme 1.1. Synthesis of $6 \mathrm{H}$-benzo[c]chromen-6-ones via $\mathrm{Bu}_{3} \mathrm{SnH}$ mediated oxidative radical cyclisation

Michael E. Jung and his co-worker synthesized these lactones via Diels-Alder cycloaddition of 4cyanocoumarins with 1-silyloxydienes. ${ }^{9}$

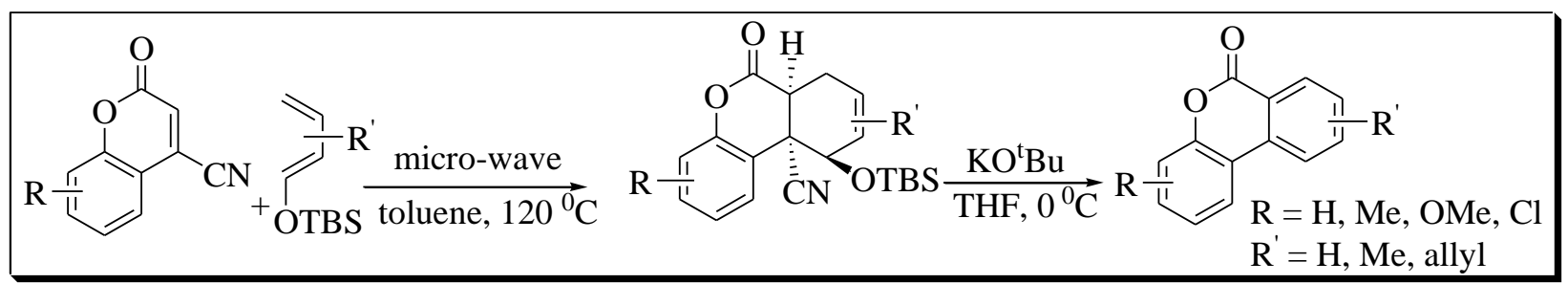

Scheme 1.2. Microwave assisted Diels-Alder reactoin towards synthesis of $6 H$-benzo[ $c]$ chromen-6-ones

Inamoto and his group developed a synthetic route to benzo[c]chromene-6-ones using rutheniumbased catalytic system via carbonylative $\mathrm{C}$-H cyclization of 2-arylphenols. ${ }^{10}$

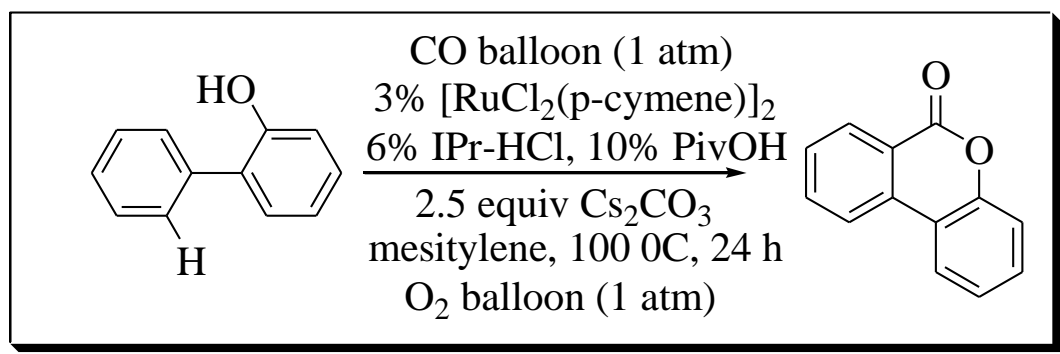

Scheme 1.3. Ruthenium-catalyzed synthesis of $6 H$ benzo[c]chromen-6-ones via carbonylative $\mathrm{C}-\mathrm{H}$ cyclization of 2-arylphenols 
Our aim was to develop an efficient, convenient and environmentally benign methodology for the synthesis of benzo[c]chromenones.

Vanker et al. developed a methodology for conversion of allylic alcohols to vinylic carbonyl compounds ${ }^{11}$ and recently, our group has reported Pd-catalyzed synthesis of benzo[c]chromenones and its analogues from 2-bromoaryl aldehydes and 2-hydroxyphenylboronic acid. ${ }^{12}$ We have efficiently combined these two ideas to construct a novel method for the one-pot synthesis of benzo[c]chromenones and their derivatives by palladium catalyzed domino Suzuki-Miyaura cross coupling and oxidative lactonization under aqueous-aerobic condition. We started our investigation by optimizing the reaction condition.

Table 1 Optimization of the reaction condition ${ }^{a, b}$

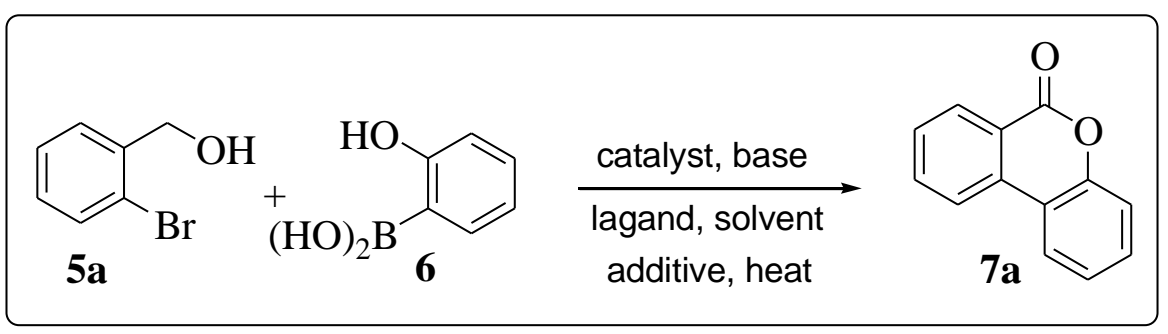




\begin{tabular}{cllllcccc}
\hline Entry & Catalyst & Base & Ligand & Solvent & Additive & Temp $\left({ }^{0} \mathrm{C}\right)$ & Time $(\mathrm{h})$ & Yield $(\%)^{\mathrm{c}}$ \\
\hline 1 & $\mathrm{PdCl}_{2}$ & $\mathrm{Cs}_{2} \mathrm{CO}_{3}$ & $\mathrm{PPh}_{3}$ & $\mathrm{DMF}$ & - & 80 & 12 & 49 \\
2 & $\mathrm{PdCl}_{2}$ & $\mathrm{Cs}_{2} \mathrm{CO}_{3}$ & $\mathrm{PPh}_{3}$ & $\mathrm{DMF}$ & - & 90 & 11 & 57 \\
3 & $\mathrm{PdCl}_{2}$ & $\mathrm{Cs}_{2} \mathrm{CO}_{3}$ & $\mathrm{PPh}_{3}$ & $\mathrm{DMF}$ & - & 110 & 12 & 51 \\
4 & $\mathrm{Pd}(\mathrm{OAc})_{2}$ & $\mathrm{Cs}_{2} \mathrm{CO}_{3}$ & $\mathrm{PPh}_{3}$ & $\mathrm{DMF}$ & - & 90 & 6 & 73 \\
5 & $\mathrm{Pd}_{2}(\mathrm{dba})_{3}$ & $\mathrm{Cs}_{2} \mathrm{CO}_{3}$ & $\mathrm{PPh}_{3}$ & $\mathrm{DMF}$ & - & 90 & 8 & 64 \\
6 & $\mathrm{Pd}(\mathrm{OAc})_{2}$ & $\mathrm{~K}_{2} \mathrm{CO}_{3}$ & $\mathrm{PPh}_{3}$ & $\mathrm{DMF}$ & - & 90 & 6 & 78 \\
7 & $\mathrm{Pd}(\mathrm{OAc})_{2}$ & $\mathrm{Na}_{2} \mathrm{CO}_{3}$ & $\mathrm{PPh}_{3}$ & $\mathrm{DMF}$ & - & 90 & 8 & 71 \\
8 & $\mathrm{Pd}(\mathrm{OAc})_{2}$ & $\mathrm{~K}_{3} \mathrm{PO}_{4}$ & $\mathrm{PPh}_{3}$ & $\mathrm{DMF}$ & - & 90 & 6 & 80 \\
9 & $\mathrm{Pd}(\mathrm{OAc})_{2}$ & $\mathrm{~K}_{3} \mathrm{PO}_{4}$ & $\mathrm{PPh}_{3}$ & $\mathrm{CH} \mathrm{H}_{3} \mathrm{CN}$ & - & 90 & 8 & 72 \\
10 & $\mathrm{Pd}(\mathrm{OAc})_{2}$ & $\mathrm{~K}_{3} \mathrm{PO}_{4}$ & $\mathrm{PPh}_{3}$ & $\mathrm{Dioxane}$ & - & 90 & 8 & 75 \\
11 & $\mathrm{Pd}(\mathrm{OAc})_{2}$ & $\mathrm{~K}_{3} \mathrm{PO}_{4}$ & $\mathrm{PPh}_{3}$ & $\mathrm{H}_{2} \mathrm{O}$ & $\mathrm{TBAB}$ & 90 & 8 & 81 \\
$\mathbf{1 2}$ & $\mathbf{P d}(\mathrm{OAc})_{2}$ & $\mathbf{K}_{3} \mathrm{PO}_{4}$ & $\mathbf{P C y}_{3}$ & $\mathbf{H}_{\mathbf{2}} \mathbf{O}$ & $\mathbf{T B A B}$ & $\mathbf{9 0}$ & $\mathbf{8}$ & $\mathbf{8 6}$ \\
13 & $\mathrm{Pd}(\mathrm{OAc})_{2}$ & $\mathrm{~K}_{3} \mathrm{PO}_{4}$ & - & $\mathrm{H}_{2} \mathrm{O}$ & $\mathrm{TBAB}$ & 90 & 8 & 71 \\
14 & $\mathrm{Pd}(\mathrm{OAc})_{2}$ & $\mathrm{~K}_{3} \mathrm{PO}_{4}$ & $\mathrm{PPh}_{3}$ & $\mathrm{H}_{2} \mathrm{O}$ & $\mathrm{TBAB}$ & 90 & 8 & 71 \\
\hline
\end{tabular}

\footnotetext{
${ }^{a}$ Reagents and conditions: $5 a(0.5 \mathrm{mmol}), 2$-hydroxyphenylboronic acid $(0.5 \mathrm{mmol})$, catalyst $(10 \mathrm{~mol}$ $\%)$, base ( 1.5 equiv.), ligand ( 0.25 equiv.), solvent ( $3 \mathrm{ml}$ ).

${ }^{\mathrm{b}}$ In a two-necked round-bottomed flask fitted with condenser.

${ }^{c}$ Isolated yields after purification through column chromatography.
}

Initially $5 \mathrm{a}(0.5 \mathrm{mmol})$ on reaction with $\mathbf{6}$ (1 equiv) in a domino fashion in presence of catalyst $\mathrm{PdCl}_{2}$ (10 mol \%), base $\mathrm{Cs}_{2} \mathrm{CO}_{3}$ (1.5 equiv), ligand $\mathrm{PPh}_{3}\left(0.25\right.$ equiv.) in $\mathrm{DMF}$ at $80^{\circ} \mathrm{C}$ for 12 hours gave $7 \mathrm{a}$ in $49 \%$ yield. Then we varied the conditions thoroughly to get the optimal condition. Firstly, the temperature was varied. The best result was obtained at $90^{\circ} \mathrm{C}$. Then different $\mathrm{Pd}$-catalysts were used. $\mathrm{Pd}(\mathrm{OAc})_{2}$ gave the best result. We also varied the base to obtain the most suitable base for our purpose. $\mathrm{K}_{3} \mathrm{PO}_{4}$ was found to be the best. Next we carried out solvent variation which showed water as the promising solvent. Lastly, we also changed ligand. $\mathrm{PCy}_{3}$ was found to be the best for our reaction giving the highest yield. In the absence of any ligand we did not get the desired product. 
Thus the optimized condition for one-pt synthesis of benzo[c]chromene-6-ones was found to be 10 mol \% of $\mathrm{Pd}(\mathrm{OAc})_{2}, 1.5$ equiv $\mathrm{K}_{3} \mathrm{PO}_{4}$, and 0.25 equiv $\mathrm{PCy}_{3}$ in water at $90^{\circ} \mathrm{C}$ for 8 hours.

Having this optimized condition in our hand, the scope of our methodology was investigated by applying the same on different substrates 5a-h (Table 2) and 8a-d (Table 3) to get benzo[c]chromene-6-ones 7a-h (Table 2 ) and napthochromenones 9a-d (Table 3) respectively.

Table 2: Synthesis of chromenones

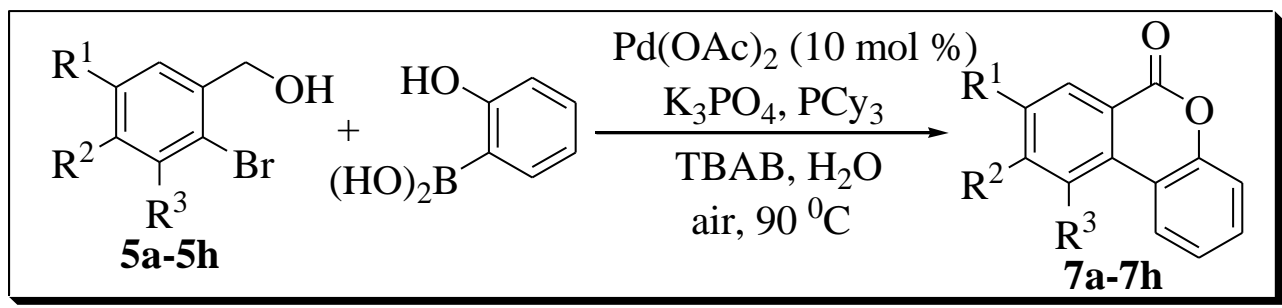


Table 2. Synthesis of benzo $[c]$ chromenones $^{\mathrm{a}}$

\begin{tabular}{|c|c|c|c|}
\hline Entry & Substrate & Product & Yield $(\%)^{b}$ \\
\hline 1 & & & 86 \\
\hline 2 & & & 84 \\
\hline 3 & & & 80 \\
\hline 4 & & & 62 \\
\hline 5 & & & 73 \\
\hline 6 & & & - \\
\hline 7 & & & - \\
\hline 8 & & & 83 \\
\hline
\end{tabular}

${ }^{a}$ Reagents and conditions: 5a-h (0.5 mmol), 2-hydroxyphenylboronic acid (0.5 mmol), $\operatorname{Pd}(\mathrm{OAc})_{2}(10$ mol \%), $\mathrm{K}_{2} \mathrm{CO}_{3}$ ( 1.5 equiv.), $\mathrm{PCy}_{3}(0.25$ equiv.), water ( $3 \mathrm{ml}$ ).

${ }^{\mathrm{b}}$ Isolated yields after purification through column chromatography. 
Table 3. Synthesis of naptha- $[c]$-chromenone derivtives ${ }^{\text {a }}$

Entry

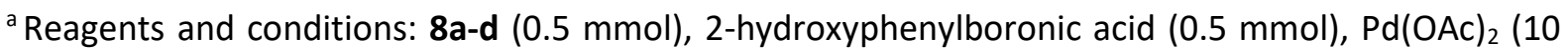
mol \%), $\mathrm{K}_{2} \mathrm{CO}_{3}$ ( 1.5 equiv.), $\mathrm{PCy}_{3}(0.25$ equiv.), water ( $3 \mathrm{ml}$ ).

${ }^{\mathrm{b}}$ Isolated yields after purification through column chromatography.

In order to study the proper sequence of the reactions for the synthesis of the substituted chromenones, a reaction (Scheme 2) was carried out between bromobenzene 10 and 2hydroxyphenylboronic acid 6 keeping all others reaction factors intact ${ }^{17}$. The reaction (Scheme 2) was completed in one and half hours and the product $\mathbf{1 1}$ was obtained in excellent yield. 


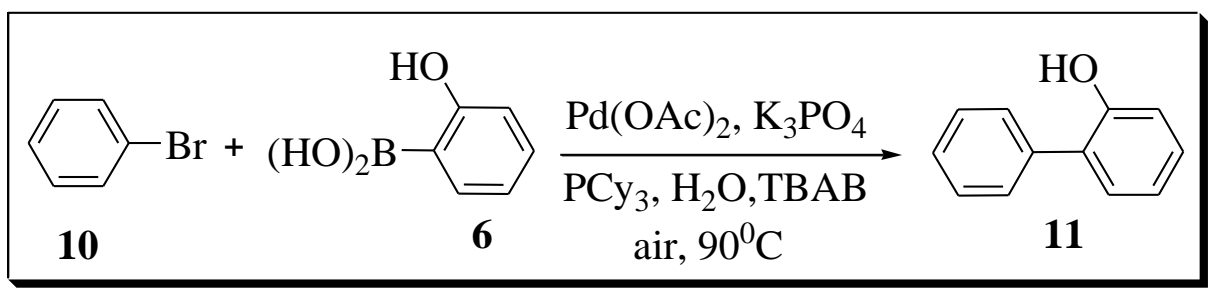

Scheme 2

Then another reaction (Scheme 3) was accomplished without 2-hydroxyphenylboronic acid 6 using 2-bromobenzyl alcohol $\mathbf{1 2}$ as the only reactant. The reaction (Scheme 2) took five hours to be completed and we got 2-bromobenzaldehyde $\mathbf{1 3}$ as the product.

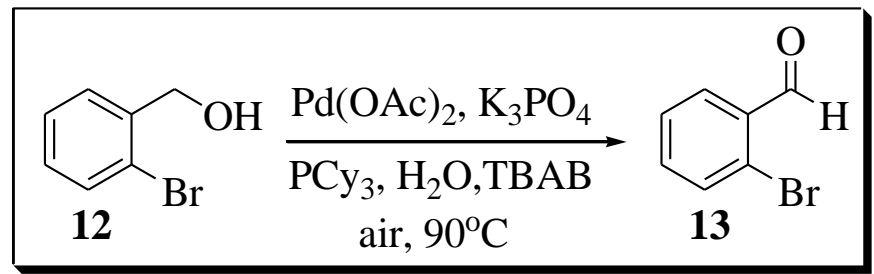

Scheme 3

From this observation it can be concluded that the Suzuki-Miyaura coupling is faster than oxidation of the alcohols to carbonyls by $\mathrm{Pd}$-nanoparticles ${ }^{25}$ under the optimized reaction condition. Thefore, the plausible reaction sequence is the formation of the intermediate $\mathbf{A}$ which then oxidises to $B$ which in turn equilibrates with the hemi acetal $\mathrm{C}$ followed by another oxidation of the alcoholic group i.e. oxidative lactonization to form the product. The sequences and the catalytic cycle for the plausible mechanism has been shown in the Scheme 3 and Scheme 4 respectively. ${ }^{40}$

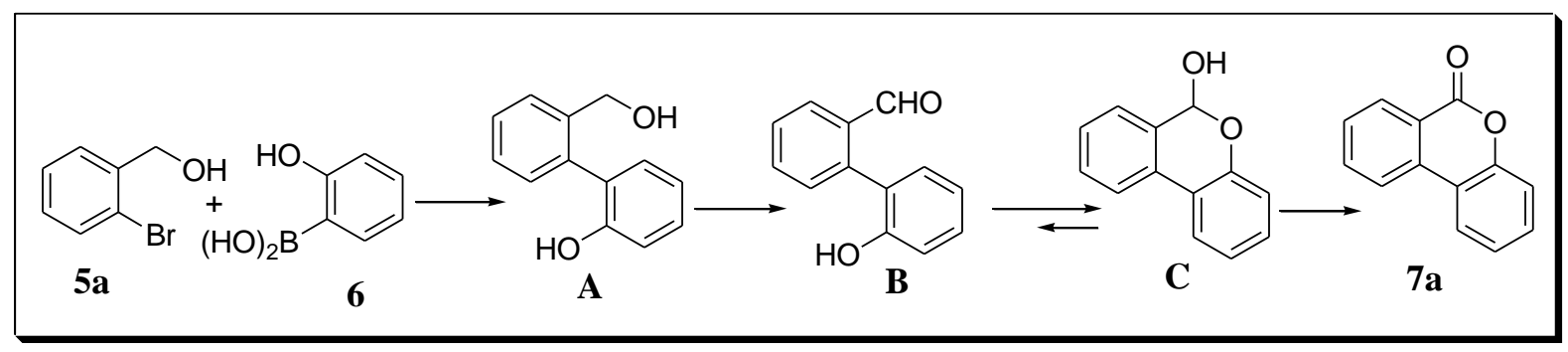

Scheme 4. Sequence of the reactions for the palusible mechanism 
However the intermediates were never isolated because whenever A converts to $B$, it rapidly equilibrates with $C$ due to the close proximity of free $\mathrm{O}^{-}$under the reaction medium. So $\mathrm{B} \& \mathrm{C}$ are formed as transient intermediate. Further investigation of the mechanistic details is underway. ${ }^{17}$

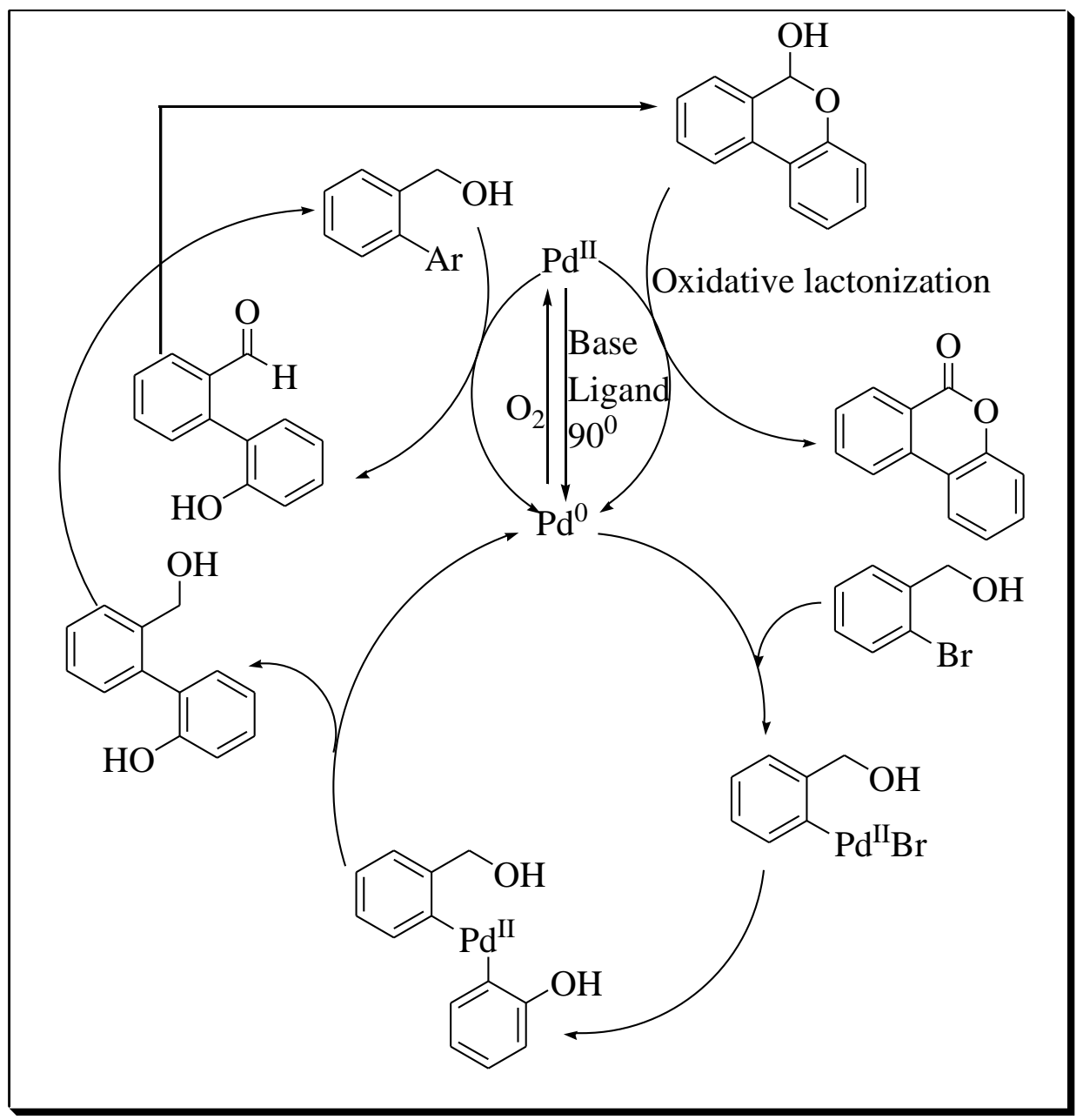

Scheme 5. A plausible mechanism for the synthesis of substituted chromenones

\section{Conclusion:}

In summary, we have developed a new convenient methodology for the synthesis of benzo[c]chromenones and its higher analogues via domino Suzuki-Miyaura cross-coupling and oxidative lactonization catalyzed by in situ generated palladium nanoparticles in water under aerobic condition. Our methodology is short and environmentally benign and substrate is readily available.

Acknowledgement : CSIR (New Delhi, India) deserves special thanks for funding this work 


\section{References:}

1. Ku, Y.-Y. et al. Asymmetric Synthesis of A-240610.0 via a New Atropselective Approach for Axially Chiral Biaryls with Chirality Transfer. Journal of the American Chemical Society 124, 4282-4286 (2002).

2. Poudel, T. N. \& Lee, Y. R. An advanced and novel one-pot synthetic method for diverse benzo[c]chromen-6-ones by transition-metal free mild base-promoted domino reactions of substituted 2-hydroxychalcones with $\beta$-ketoesters and its application to polysubstituted terphenyls. Organic \& Biomolecular Chemistry 12, 919-930 (2014).

3. Hosoya, T., Takashiro, E., Matsumoto, T. \& Suzuki, K. Total Synthesis of the Gilvocarcins. Journal of the American Chemical Society 116, 1004-1015 (2002).

4. Phukan, P., Bawari, M. \& Sengupta, M. Promising neuroprotective plants from northeast India. Int J Pharm Pharm Sci 7, 28-39 (2015).

5. Ray, P. et al. Microenvironment-sensing, nanocarrier-mediated delivery of combination chemotherapy for pancreatic cancer. Journal of Cell Communication and Signaling (2019) doi:10.1007/s12079-019-00514-w.

6. Ray, P. et al. Stabilisation of small mono- and bimetallic gold-silver nanoparticles using calix[8]arene derivatives. New Journal of Chemistry (2018) doi:10.1039/c8nj02451k.

7. Ray, P. et al. Size-Transformable, Multifunctional Nanoparticles from Hyperbranched Polymers for Environment-Specific Therapeutic Delivery. ACS Biomaterials Science and Engineering (2019) doi:10.1021/acsbiomaterials.8b01608.

8. Ray, P. et al. PEG-b-poly (carbonate)-derived nanocarrier platform with $\mathrm{pH}$-responsive properties for pancreatic cancer combination therapy. Colloids and Surfaces B: Biointerfaces (2019) doi:10.1016/j.colsurfb.2018.10.069.

9. Ray, P., Ferraro, M., Haag, R. \& Quadir, M. Dendritic Polyglycerol-Derived NanoArchitectures as Delivery Platforms of Gemcitabine for Pancreatic Cancer. Macromolecular Bioscience (2019) doi:10.1002/mabi.201900073.

10. Brahma, S., Ray, P., Singha, R. \& Ray, J. K. Visible colourimetric and ratiometric fluorescent chemosensors for $\mathrm{Cu}(\mathrm{II})$ and $\mathrm{Ni}(\mathrm{II})$ ions. Asian Journal of Chemistry (2016) doi:10.14233/ajchem.2016.19578.

11. André, E. et al. A New, Simple and Versatile Strategy for the Synthesis of Short Segments of Zigzag-Type Carbon Nanotubes. Chemistry - A European Journal (2016) doi:10.1002/chem.201503693. 
12. Confeld, M. I. et al. Targeting the tumor core: hypoxia-responsive nanoparticles for the delivery of chemotherapy to pancreatic tumors. Molecular pharmaceutics 17 , 2849-2863 (2020).

13. Brahma, S., Ray, P. \& Ray, J. K. Synthesis of azirines containing aldehyde functionality and their utilization as synthetic tools for five membered oxazoles and isoxazoles (vol 45, pg 311, 2008). JOURNAL OF HETEROCYCLIC CHEMISTRY 58, 1388 (2021).

14. Ray, P. Curing Cancer with Nanotherapy Continues to be an Elusive Goal. Journal of Immunological Sciences 5, (2021).

15. Ray, P. Interactions of nitrogen and hydrogen with various $1 \mathrm{D}$ and $3 \mathrm{D}$ carbon materials probed via in-situ vibrational spectroscopy. (2016).

16. Ray, J. K. et al. Palladium-catalyzed expedient Heck annulations in 1-bromo-1, 5-dien3-ols: Exceptional formation of fused bicycles. Tetrahedron Letters 60, 931-935 (2019).

17. Ray, D. et al. Palladium-Catalyzed Intramolecular Oxidative Heck Cyclization and Its Application toward a Synthesis of $( \pm)$ - $\beta$-Cuparenone Derivatives Supported by Computational Studies. Synthesis 45, 1261-1269 (2013).

18. Chaudhuri, S., Maity, S., Roy, M., Ray, P. \& Ray, J. K. A Vinyl Radical Cyclization Route to Hydroxycyclohexene Fused Carbocycles. Asian Journal of Chemistry 28, (2016).

19. Singha, R., Roy, S., Nandi, S., Ray, P. \& Ray, J. K. Palladium-catalyzed one-pot SuzukiMiyaura cross coupling followed by oxidative lactonization: A novel and efficient route for the one-pot synthesis of benzo[c]chromene-6-ones. Tetrahedron Letters (2013) doi:10.1016/j.tetlet.2012.11.144.

20. Ray, P., Kale, N. \& Quadir, M. New side chain design for $\mathrm{pH}$-responsive block copolymers for drug delivery. Colloids and Surfaces B: Biointerfaces 200, 111563 (2021).

21. Ray, J. K. et al. Pd-catalyzed intramolecular sequential Heck cyclization and oxidation reactions: a facile pathway for the synthesis of substituted cycloheptenone evaluated using computational studies. New Journal of Chemistry 41, 278-284 (2017).

22. Kaboudin, B., Momen, T., Kazemi, F. \& Ray, P. Novel $\beta$-Cyclodextrin Functionalized Core-Shell Fe304 Magnetic Nanoparticles for the Removal of Toxic Metals from Water. (2021).

23. Ray, P., Wang, C. Y. \& Lueking, A. D. Kinetic studies of N2 adsorption on polymers of intrinsic microporosity (PIM-1) to study the effect of the $\mathrm{CN}$ functionalities. in Separations Division 2016-Core Programming Area at the 2016 AlChE Annual Meeting 280-288 (AIChE, 2016).

24. Ghosh, M., Ahmed, A., Dhara, S. \& Ray, J. K. Synthesis of phenanthridine and its analogues via aerobic ligand-free domino Suzuki coupling-Michael addition reaction 
catalyzed by in situ generated palladium-nanoparticles in water. Tetrahedron Letters 54, 4837-4840 (2013).

25. Ghosh, M., Ahmed, A., Dhara, S. \& Ray, J. K. Synthesis of phenanthridine and its analogues via aerobic ligand-free domino Suzuki coupling-Michael addition reaction catalyzed by in situ generated palladium-nanoparticles in water. Tetrahedron Letters 54, 4837-4840 (2013).

26. Roy, B. C., Gupta, M. D. \& Ray, J. K. Studies on Conducting Polymers. 1. AnilineInitiated Polymerization of Nitroanilines. Macromolecules (1995) doi:10.1021/ma00110a001.

27. Ray, P., Gidley, D., Badding, J. v \& Lueking, A. D. UV and chemical modifications of polymer of Intrinsic Microporosity 1 to develop vibrational spectroscopic probes of surface chemistry and porosity. Microporous and Mesoporous Materials 277, 29-35 (2019).

28. Ray, P., Gray, J. L., Badding, J. v \& Lueking, A. D. High-pressure reactivity of triptycene probed by Raman spectroscopy. The Journal of Physical Chemistry B 120, 1103511042 (2016).

29. Ray, P., Angela, L. D., John, B., Crespi, V. \& Xu, E. Nitrogen Raman Spectroscopy as a tool for micro-scale pore size determination for carbon nanomaterials. in ABSTRACTS OF PAPERS OF THE AMERICAN CHEMICAL SOCIETY vol. 250 (AMER CHEMICAL SOC 1155 16TH ST, NW, WASHINGTON, DC 20036 USA, 2015).

30. Sarker, N. C. et al. Development of functional nanomaterials from wheat bran derived arabinoxylan for nucleic acid delivery. Journal of agricultural and food chemistry 68, 4367-4373 (2020).

31. Ray, P., Xu, E., Crespi, V. H., Badding, J. v \& Lueking, A. D. In situ vibrational spectroscopy of adsorbed nitrogen in porous carbon materials. Physical Chemistry Chemical Physics 20, 15411-15418 (2018).

32. Ghosh, A. et al. Zoledronic acid-induced suppression of invasive phenotypes of pancreatic cancer cells is mediated through downregulation of CYR61/CCN1. (2019).

33. Wang, C.-Y. et al. Influence of gas packing and orientation on FTIR activity for CO chemisorption to the Cu paddlewheel. Physical Chemistry Chemical Physics 17, 2676626776 (2015).

34. Clément, M. et al. Synthesis and NMR study of trimethylphosphine gold (i)-appended calix [8] arenes as precursors of gold nanoparticles. Inorganic Chemistry Frontiers 7, 953-960 (2020).

35. Das, A. et al. CCN5 activation by free or encapsulated EGCG is required to render triple-negative breast cancer cell viability and tumor progression. Pharmacology research \& perspectives 9 , e00753 (2021). 
36. Ray, P. et al. pH-sensitive nanodrug carriers for codelivery of ERK inhibitor and gemcitabine enhance the inhibition of tumor growth in pancreatic cancer. Molecular Pharmaceutics 18, 87-100 (2020).

37. Ray, P. et al. Microenvironment-sensing, nanocarrier-mediated delivery of combination chemotherapy for pancreatic cancer. Journal of cell communication and signaling 13, 407-420 (2019).

38. Abdullah, C. S. et al. Chemical architecture of block copolymers differentially abrogate cardiotoxicity and maintain the anticancer efficacy of doxorubicin. Molecular pharmaceutics 17, 4676-4690 (2020).

39. Lueking, A. D. et al. IV. H. 10 Exploration of Novel Carbon-Hydrogen Interactions.

40. Stahl, S. S. Palladium Oxidase Catalysis: Selective Oxidation of Organic Chemicals by Direct Dioxygen-Coupled Turnover. Angewandte Chemie International Edition 43, 3400-3420 (2004). 